\title{
LA MICROTEXTUALIDAD EN EL TEATRO BREVE ACTUAL: DEL TEATRO BREVE AL MICROTEATRO ESPAÑOL Y SU REVERSO CON LA MICROFICCIÓN HISPÁNICA
}

\author{
THE MICRO-TEXTUALITY IN CURRENT SHORT THEATER: \\ FROM THE SHORT THEATER TO THE SPANISH MICRO-THEATER \\ AND HIS REVERSE WITH HISPANIC MICRO-FICTION \\ JoRge Gómez VÁzquez \\ Universidad Nacional de Educación a Distancia \\ jorgegrual@hotmail.com
}

Fecha de Recepción: 20-07-2017

Fecha de Aceptación: 01-02-2018

\section{RESUMEN}

Dentro del teatro breve actual en España, establecemos una distinción entre el teatro breve y el denominado microteatro. Al respecto, tenemos en cuenta la extensión de tales textos dramáticos y su duración en la escenificación. Tras estudiar el fenómeno del microteatro español, estudiamos la microficción hispánica. Aquí analizamos los casos de semejanza microtextual con el microteatro, tal y como sucede con la microficción dialógica o dramática.

Palabras Clave: Teatro breve; microteatro; mini/microficción; microrrelato; microtexto.

\section{AbStract}

In the current short theater in Spain, we establish a distinction between short theater and so-called micro-theater. Around this, we indicate the extension of these dramatic texts and their duration in the staging. After studying the phenomenon of the Spanish mi- 
cro-theater, we studied Hispanic micro-fiction. Here we analyze the cases of micro-textual similarity with the micro-theater, as it happens with dialogic or dramatic micro-fiction.

KEY WORDS: Short theater; micro-theater; mini/micro-fiction; micro-story; micro-text.

\section{INTRODUCCIÓN}

La presencia que tienen las piezas dramáticas breves en nuestra tradición literaria es constante. Estas obritas dramáticas recorren la historia literaria española con diferentes nombres: autos, pasos, entremeses, sainetes, pasillos... Teatro breve producido por un sinfín de importantes autores, tales como Juan del Encina, Lope de Rueda, Cervantes, Quevedo, Barbadillo, Calderón, Ramón de la Cruz, González del Castillo, Arniches, Benavente, Valle-Inclán, Lorca, etc., por nombrar a unos pocos, hasta llegar a las nuevas generaciones de dramaturgos como Francisco Nieva, Eduardo Quiles, José Luis Alonso de Santos, Alfonso Vallejo, Juan Mayorga, etc. Todos ellos se han servido (o se sirven) del molde dramático breve.

Respecto al teatro breve en España, se podrían señalar cinco etapas históricas ${ }^{1}$ : a) etapa fundacional o renacentista (autos, églogas, pasos y, finalmente, entremeses); b) etapa de madurez o barroca (en torno al entremés van surgiendo otras piezas teatrales: la loa entremesada, la jácara entremesada, la mojiganga y el baile dramáticos, etc.); c) etapa dieciochesca (el entremés se convierte en sainete); d) fines del siglo XIX y primeros años del xx (irrupción del género chico y unión de piezas breves al teatro musical. Por otro lado, los sainetes de Arniches bordean lo costumbrista y la crítica social); e) etapa contemporánea (autores como Benavente, Lorca o Valle-Inclán recuperan piezas dramáticas breves como la farsa, el entremés, la jácara, etc., renovándolas e introduciendo en ellas temas muy serios y críticos, superando el costumbrismo intrascendente, lo cual abre nuevas posibilidades al género y es aprovechado, sobre todo a partir de los sesenta, por los dramaturgos de la llamada neovanguardia como José Ruibal, Antonio Martínez Ballesteros o Francisco Nieva).

Por otra parte, alrededor de las vanguardias históricas del primer tercio del xx, proliferan las experimentaciones literarias e hibridaciones genéricas de toda índole, especialmente en torno a la eclosión literaria de la microtextualidad (cf. Ródenas, 2009), a partir de la cual comienzan a advertirse también precursores microdramas híbridos que exacerban la común extensión del teatro breve o la acostumbrada extensión de las piezas dramáticas breves tradicionales, tal y como ya practican y experimentan en España, por ejemplo, Juan Ramón Jiménez, con algunos cuadros mínimos dialógico-poemáticos, o García Lorca, con ciertos Diálogos hiperbreves dramatizados y de cierta narratividad poética. Tales llamativas formulaciones, según percibe y apunta Andres-Suárez (2010; 2014), resultan fenómenos microtextuales híbridos de estructuras teatrales, pero de cierta narratividad literaria emparentable al fenómeno denominado después como microrrelato (o minificción). En todo caso, según Andres-Suárez (2010: 141), el legado de estos productores de precursores microtex-

\footnotetext{
${ }^{1}$ Seguimos lo señalado por Huerta Calvo (2008: 19-26) en su Historia del teatro breve en España.
} 
tos híbridos dramatizados, unido al de otros posteriores productores de microrrelatos proteicos de apoyaturas dialógicas o teatrales, tales como Max Aub (en su libro Crímenes ejemplares, 1957) o Javier Tomeo (en Historias mínimas, 1988),

va a ser recogido años más tarde por una plétora de jóvenes dramaturgos, fuertemente atraídos por el teatro breve, así como por la irracionalidad poética que llegó de la mano del surrealismo, primero, y, posteriormente, de la literatura del absurdo. Por ejemplo, el dramaturgo valenciano José Sanchís Sinisterra, en «El Teatro Fronterizo. Manifiesto (latente)» [1980], postula unos principios estéticos, constructivos e ideológicos que regirán, en adelante, su dramaturgia, basados en la investigación sobre las fronteras del teatro, lo no teatral y su conversión en hecho escénico, así como sobre las dramaturgias menores como alternativa del teatro establecido. Con ello, este autor marca la senda por la que se adelantarán numerosos dramaturgos experimentales, como José Luis Alonso de Santos, Ignacio Amestoy, Jesús Campos, David Desola, Ana Diosdado, Jerónimo López Mozo, Juan Mayorga, Alberto Miralles, Diana de Paco Serrano, Itziar Pascual, Paloma Pedrero, Concha Romero, Sergio Rubio, y algunos más. Dichos autores escriben piezas que se reducen frecuentemente a un acto y que apuestan por la hiperbrevedad, la elipsis, la concisión y la intensidad dramática.

Desde el punto de vista formal, suelen ser muy breves y muchas de ellas oscilan entre las dos páginas y la media página, lo que las acerca a la extensión del microrrelato; ello explica que estén sometidas a un proceso severo de simplificación y condensación del tiempo, el espacio (el escenario único), y los personajes... (Andres-Suárez, 2010: 141-142)

Así pues, aquellas formulaciones microdramáticas híbridas podrían entenderse como tentativos antecedentes de lo que hoy en día resulta ser un singular fenómeno dentro del panorama español del teatro breve actual: el microteatro, el cual comparte semejanzas extensionales y fronterizas con la microficción o microrrelato proteico de aspecto dramático o de carácter dialógico, pero que, sin embargo, aquel se concibe no solo para su lectura, sino también, o más aún, para su representación, y generalmente suele ser producido por dramaturgos españoles actuales, tales como algunos de los señalados por Andres-Suárez, así como por otros tantos dramaturgos, entre los cuales destacamos, por ejemplo, la producción de «pulgas dramáticas»² de José Moreno Arenas o algunas micropiezas de Alfonso Zurro, quien asumió la dirección del espectáculo 60 obras de 1 minuto de 60 autores dramáticos andaluces, estrenada en Sevilla el 27 de marzo de 2006 (y publicadas en libro ese mismo año), así como otras escenificaciones de microteatro español ofrecidas en semejantes espectáculos conjuntos, alguno de los cuales también ha dirigido después Zurro, tal como, por ejemplo, el recogido en Día Mundial del Teatro.Sevilla 2010. En general, este tipo de micropiezas dramáticas representadas se pueden encontrar recogidos en libros compilatorios, tanto colectivos como de una dramaturgo concreto, que conforman la escenificación conjunta de ellas en diversos espectáculos teatrales celebrados en España, algunos de estos convocados para protestar o reivindicar sobre diversos asuntos de la actualidad política y social, tales como, por ejemplo, Teatro contra la guerra (2003) o Grita, tengo sida (2006). Respecto a la consulta de publicaciones sobre teatro breve actual en los que se pueden ha-

\footnotetext{
${ }^{2}$ Respecto a la denominación y definición dadas por Adelardo Méndez Moya, remitimos a su prólogo titulado «A propósito de pulgas dramáticas: Trece minipiezas y un happening de Javier García Teba» (Méndez, 2003: 15-21).
} 
llar abundantes ejemplos de microteatro, remitimos a la «Bibliografía del teatro breve español en los inicios del siglo XxI», en donde Isabel Cristina Díez Ménguez (2012) recoge un extenso repertorio bibliográfico con obras de teatro breve publicadas en España y en lengua española, desde el año 2000 al 2010, el cual contiene «más de mil trescientas, pertenecientes a seiscientos autores [españoles]» (Díez, 2012: 205).

Por otro lado, advertimos que nuestra distinción y definición de microteatro, basada en la extensión del texto dramático (y en una representación no superior al minuto), difiere del término microteatro empleado en algún que otro estudio de microrrelato ${ }^{3}$ o minificción. Nosotros, en cambio, vamos a tratar aquí la específica y propia producción de micropiezas dramáticas representables (y representadas) dentro del panorama del teatro breve actual en España, tal y como distinguimos, definimos y ejemplificamos dentro del correspondiente subapartado titulado «microteatro» ${ }^{4}$. No obstante, debido a los desplazamientos entre ambos fenómenos, en el último apartado nos ocuparemos — desde la perspectiva del microrrelato o minificción hispánica- de los límites borrosos entre microrrelato (dialógico o dramático) y microteatro (de intenciones textuales más prosísticas).

\section{DISTINCIONES TENTATIVAS DENTRO DEL TEATRO BREVE ACTUAL}

Nuestro teatro breve, como ya se ha apuntado más arriba, tiene una serie de características que van cambiando a medida que la sociedad y la época varían, aunque conserva una serie de rasgos que lo identifican como un género común. Tal vez sea el humor y su carácter popular los que, con matices y diferencias, resultan más perceptibles hasta la apuntada época contemporánea, en donde se abre un camino de renovación y desarrollo del teatro breve en España hasta la época actual.

\footnotetext{
3 Así, por ejemplo, la propia Andres-Suárez, en su artículo titulado «Transversalidad de las formas literarias breves», señala lo siguiente: «Cuando hablamos de microteatro nos referimos a unos textos muy breves que, aunque presentan forma teatral, es decir, poseen acotaciones, diálogos o monólogos, no parecen haberse concebido para la representación, sino para la lectura» (Andres-Suárez, 2014). En general, Andres-Suárez alude aquí a ejemplos estudiados por ella (cf. Andres-Suárez, 2010) de lo que ha venido denominando, dentro de sus estudios de microrrelato, como «microteatro narrativo» (entre otras definiciones), que vendrían a ser, más bien, ejemplos de microrrelatos proteicos de apoyaturas dialógicas o con elementos de textos teatrales.

${ }^{4}$ Sobre el término «microteatro» informa Javier Tomeo en el prólogo de sus Historias mínimas (1988), en donde confiesa aquí que, en lugar de este título, tenía pensado titularlo como «Microteatro psicopático», descartado por ser «un nombre, sin duda, bastante duro» (Tomeo, 19962: 8). En 1977, Antonio Beneyto publica algunas historias mínimas en su antología de aquel año, rotulándolas «Microteatro psicopático» (cf. Andres-Suárez, 2010: 196). Por otro lado, la propia Andres-Suárez, pionera en la investigación del microrrelato español, ya estudió los microrrelatos de Tomeo en Historias mínimas como ejemplos de una de las «Tendencias del microrrelato español» concebido según técnicas propias de los textos teatrales (cf. Andres-Suárez, 2001), y luego ha vuelto sobre ellos en ulteriores estudios de microrrelato (cf. Andres-Suárez, 2010: 189-219). Por otra parte, tanto la terminología alusiva y sinónima como el propio fenómeno del micro/miniteatro actual muestra cierta o gran influencia respecto al previo fenómeno consolidado del microrrelato o microficción hispánica. En cualquier caso, el término «micro/miniteatro» se ha difundido en estudios de teatro breve, tales como, por ejemplo, los de M. a Jesús Orozco Vera, así como ha sido utilizado por otros dramaturgos, incluso aparece destacado en el teatro madrileño denominado «Microteatro» (cf. en http://microteatro.es/ [07-07-17]), aunque este «microteatro» vendría a estar entre el teatro breve y el microteatro, pues su representación está pensada para durar 15 minutos.
} 
Así pues, a partir de los dramaturgos neovanguardistas hasta las nuevas promociones (José Luis Alonso de Santos, Rafael Gordon, Paloma Pedrero, Ernesto Caballero, Juan Mayorga, Itziar Pascual, etc.), el teatro breve adquiere una gran autonomía y presencia no secundaria respecto al teatro largo, el cual goza ya del respeto y aprecio por parte de la crítica especializada. En este sentido, señalamos aquí, por ejemplo, dos antologías de teatro breve actual con sendos estudios introductorios: Teatro breve entre dos siglos, en edición y compilación de Virtudes Serrano (2004), así como Teatro breve actual (2013), en edición de Francisco Gutiérrez Carbajo, quien ofrece una selección de cincuenta obras de diversos autores representativos del panorama actual del teatro breve en España, y cuya destacable introducción proporciona, además, un detallado estudio sobre las diversas modalidades discursivas de la dramaturgia. Por otra parte, destacamos también el xx Seminario Internacional del SELITEN@T de la UNED, dirigido por José Romera Castillo, dedicado a El teatro breve en los inicios del siglo xxi (ed. Romera 2011), en cuyas actas se podrán encontrar numerosos estudios y bibliografía sobre el tema.

Respecto a la temática del teatro breve en general, Orozco Vera señala lo siguiente:

[refleja] las inquietudes del hombre y de la mujer del siglo xxi. En sus obras se plasman los efectos de un mundo caótico, deshumanizado y sumamente violento; un espacio inhóspito que se proponen mejorar los escritores, los creadores de textos dramáticos, entregando su mensaje, en clave de comedia, tragedia o drama, a sus lectores o espectadores. Por otra parte, con respecto a las preferencias estéticas, cabe reseñar la variedad, la heterogeneidad que caracteriza a este teatro breve que retoma la tendencia neorrealista y cultiva también la experimentación trazada por el surrealismo, sin olvidar el simbolismo y el teatro del absurdo. (2006: 729)

Finalmente, advertimos que atendemos, con ciertas adaptaciones nuestras, a las distinciones establecidas por Lauro Zavala (2004: 86-106) sobre el cuento corto, muy corto y ultracorto para establecer un paralelismo respecto al teatro breve actual y sus posibles distinciones según sea su extensión (y duración). Sin embargo, nosotros hacemos una división bipartita: teatro breve y microteatro. Ahora bien, dentro del teatro breve actual, señalamos un subtipo de transición intermedio: el teatro muy corto.

\subsection{El teatro breve actual}

Este teatro breve - como en el de Rafael Gordon ${ }^{5}$, por ejemplo- puede albergar ya un tratamiento claramente diferenciado del teatro breve originario. Por otro lado, la extensión de las piezas breves viene a ser la de un acto desarrollado en más de seis páginas, incluso algunas de estas obritas pueden incluir además un prólogo y un epílogo — como en «Entrenamiento» de Gordon (2006: 43), o en «La falsa muerte de Jaro el Negro» ${ }^{6}$ de Martín Iniesta- y alcanzar fácilmente las veinte páginas o más. En su mayor extensión y duración, el teatro breve, según Díez Ménguez, «no suele exceder las cuarenta páginas y en escena no sobrepasan los noventa minutos» (2012: 207).

\footnotetext{
5 Teatro breve (1992-2004), de Rafael Gordon (2006).

${ }^{6}$ Recogido en Teatro breve entre dos siglos (cf. Serrano, 2004: 117-135).
} 
Este teatro breve, con una extensión textual superior a las 2500 palabras, aproximadamente, y una duración no inferior a los 15 minutos, puede desarrollar una historia, incluso usando el esquema básico de planteamiento, nudo y desenlace. Aunque, tal vez, lo normal sea situarnos en el problema y desarrollarlo hasta el final. Esta extensión vendría a ser la más usada por nuestros dramaturgos. Todas las obritas dramáticas que se recogen en la antología de Virtudes Serrano (2004) pertenecen a esta categoría (aunque algunas de ellas, como «El buen vecino» de Juan Mayorga, se aproximan más al teatro muy corto). También estarían en este grupo algunas de las piezas mínimas que vienen apareciendo anualmente (desde 1987) en la revista valenciana Art teatral $^{7}$, dirigida por Eduardo Quiles (quien publica también piezas mínimas suyas). Dicha revista se ha especializado en el teatro breve, y tiene por objetivo la difusión de dramaturgos contemporáneos a través de la publicación de su teatro breve. Además de editar un promedio de diez obras por número, se publican también estudios sobre la importancia de los géneros breves en la historia del teatro y en la obra de un autor teatral. Hasta la fecha, la revista lleva publicadas un total de doscientas obras breves, incluidos monólogos y un buen número de ensayos.

\subsubsection{El teatro muy corto}

La extensión textual de este teatro no suele sobrepasar las 2500 palabras, aproximadamente, ni bajar del medio millar, lo cual puede abarcar unas tres o seis páginas (aunque esto puede variar según características de publicación). Tal vez sea este un teatro concebido para una duración en torno a los 10 o 15 minutos, especializado en ese cuarto de hora. No obstante, debido a las características especiales del teatro, los textos dramáticos pueden ser más extensos y durar en escena menos tiempo (y viceversa). En cualquier caso, este sería un teatro de transición entre la extensión textual convencional del teatro breve y la mínima extensión y duración del microteatro (y puede ser percibido este teatro muy corto, dependiendo del número de palabras y/o de la duración de su representación, como teatro breve o como microteatro). Estableciendo un paralelismo con el género del cuento, vendría a ser lo que en el panorama anglosajón se ha denominado «short shorts», que vienen a ser aquellos relatos/cuentos breves/cortos de una extensión oscilante entre las 1.000 y 2.500 palabras, aproximadamente. Su reducido tamaño no le permite más que ir a lo sustancial directamente; el final puede ser abrupto o sorpresivo, aunque no necesariamente. Se recurre a veces al monólogo. Cuando hay más de un personaje, no suelen pasar de dos. Éstos suelen ser descritos con nombres genéricos o diferenciados por sus oficios o trabajos (Él, Ella; Joven, Viejo; Alto, Bajo; Camarero, Cliente; etc.). No obstante, algunas de estas características muy generales pueden diferir o variar, ya que en el propio microteatro varía aquello. Por otro lado, aquí solo da tiempo a construir una escena altamente significativa. Un ejemplo de este tipo de teatro muy breve lo encontra-

\footnotetext{
7 Véase www.artteatral.com . Algunos números de la revista —como el n. ${ }^{\circ} 15$ (2001), n. ${ }^{\circ} 17$ (2002), n. ${ }^{\circ} 18$ (2003; sólo ensayos) o los tres últimos números, del 21 al 23 (2007-08), cuyas ediciones son digitales- se pueden leer en internet (visto el 07-07-17).
} 
mos, por ejemplo, en algunos de los Cuadros de amor y humor, al fresco ${ }^{8}$, de José Luis Alonso de Santos.

En este grupo también se encontrarían muchas de las piezas dramáticas publicadas en la citada revista valenciana Art teatral, tales como, por ejemplo: «Soledad en un banco», de Margarita Reiz (n. ${ }^{\circ}$ 17, 2 páginas y media, con 1278 palabras); «Herida», de Itziar Pascual (n. ${ }^{\circ}$ 15, 3 págs.); «Buterfly», de Pedro Catalán (n. ${ }^{\circ} 17,3$ págs.); «A la puerta del mercado», de Eduardo Quiles (n. ${ }^{\circ}$ 15, 4 págs.); «Vivir en paz», de Martínez Ballesteros (n. ${ }^{\circ} 15$, 4 págs.), etc.

\subsection{El microteatro actual ${ }^{9}$}

Si establecemos un paralelismo con el género del microrrelato o minificción, estas micropiezas no superarían la extensión textual de las 300 palabras o la hoja impresa, aproximadamente (aunque lo más clasificatorio aquí es el cómputo de palabras y la concepción de las micropiezas para ser representadas en torno a un minuto ${ }^{10}$, en lugar de un cuarto de hora, por ejemplo). El microteatro sería, efectivamente, aquella

pieza más breve, la micropieza, pieza mínima, pulga dramática o lo que Jesús Campos ha denominado como un «transgénico», la del brevísimo, de apenas unas cuantas líneas, cuya situación dramática se resuelve en el corto espacio de un minuto. (Díez, 2012: 207)

En este sentido, se podría establecer un paralelismo respecto al tiempo de representación del microteatro con el de los habituales anuncios de la televisión, los cuales no suelen durar más de un minuto o poco más. Asimismo, podríamos relacionarlo con el cine comprimido difundido en internet, también llamado minipelículas, videominuto, cibercinema, etc. ${ }^{11}$ Igualmente, el microteatro puede resultar emparentable con ciertos sketchs audiovisuales de apenas un minuto de duración. En cambio, siguiendo con tales analogías, podríamos asemejar el teatro breve al cortometraje (cf. Gutiérrez Carbajo, 2006), cuya duración suele rondar el cuarto de hora, media hora o algo más. A su vez, respecto a la extensión del texto del teatro breve convencional, podríamos equipararla con la extensión narrativa del género cuento, mientras que la del microteatro, tal como ya señalamos, se asemeja a la extensión microtextual del microrrelato o minificción.

\footnotetext{
${ }^{8}$ Para un detallado estudio sobre la obra de Alonso de Santos y sobre estos cuadros dramáticos, en relación además con el relato fílmico, remitimos a la edición realizada por Gutiérrez Carbajo (2006).

${ }^{9}$ Respecto a las micropiezas que expondremos en este apartado, indicamos lo siguiente: las dos primeras están recogidas en sus respectivos libros de autor. Por otro lado, las citadas con el año 2006 hacen referencia a 60 obras de un minuto de 60 autores dramáticos andaluces (2006a), excepto la de Francisco Nieva, incluida en Grita, tengo sida (2006b). Finalmente, dos de las últimas micropiezas seleccionadas están publicadas en Teatro contra la guerra (2003)

${ }^{10}$ No obstante, compartimos lo que dice Eduardo Quiles (2001): «Una minipieza no lo es por el reducido tiempo que dura una acción dramática, sino porque contiene sustancia teatral y pasó por el filtro de la síntesis». Cf. «Teatro corto. ¿Cuestión de folios o de síntesis?», en www.artteatral.com (N. ${ }^{\circ}$ 15, año 2001).

${ }^{11}$ Se pueden encontrar buenos ejemplos de micropelículas en www.notodofilmfest.com (07-07-17).
} 
Asimismo, para poder clasificar claramente estas micropiezas como microteatro, y no como microficción, deben haberse concebido para su representación (o al menos albergar esa intención productiva textual), y no solamente para su publicación y lectura (con intereses entonces más puramente prosísticos).

El índice mínimo del microteatro sería aquel cuya microtextualidad no suponga o implique ausencia — tal como señala Quiles (2001) — «de la esencia del drama». En torno a su distinción, el microtexto dramático debería presentar marcas mínimas o suficientes como para reflejar ciertas intenciones de representatividad dramatizables, no solo a través de ese código textual del género dramático (configuración del espacio escénico, acotaciones o didascalias, personajes, autorreferencias teatrales o indicadores metadiscursivos, conflictos, etc.), sino también que el microtexto dramático no resulte tan inestable como para proyectarse ya sobre otro fenómeno microtextual literario (microficción, poema en prosa, etc.). Aparte de esto, los índices pragmáticos contextuales (lugar de publicación, por ejemplo) e intencionales (autoriales, concepción para su representación) ayudarán también a su clasificación; así como también, claro está, si la micropieza dramática ha sido representada.

Para ir comprobando mejor todo lo indicado, vamos a ofrecer ejemplos de microteatro. Comenzamos, pues, con dos micropiezas muy distintas entre sí, pero ambas muy representativas de los límites del fenómeno del microteatro. La primera de ellas es «La pluma» de Alfonso Zurro, cuya micro-bufonería se sostiene en el escenario con una acción y frase mínimas. Tal vez sea esta una de las micropiezas dramáticas más hiperbreves (tanto en su extensión textual como en su duración escenificable). La segunda es una pulga dramática de José Moreno Arenas, titulada «La gata»; es una didascalia sobre las acciones que acontecerán en el escenario. En esta micro-obra de Arenas no se llega a pronunciar palabra alguna, salvo un ronroneo. Así pues, los dos ejemplos de microteatro mencionados son los siguientes:

\section{LA PLUMA}

(Entra el Hombre. Ve una pluma en el suelo. La coge.)

HOMBRE. La pluma de un Ángel. iQué suerte!

(Sale corriendo.)

(Zurro, 1994: 85)

\section{LA GATA}

Personajes: TORRE, GATA

\section{ACTO ÚNICO}

El escenario carece de decoración.

(En el centro, una torre inexpugnable. Aparece una gatita de pelo negro aterciopelado. Levantando su prepotente cola roza su lomo una y otra vez en las estructuras de la torre. Esta se desploma. Es el cadáver de un hombre. La gata, provocadora e «ingenua», se dispone a abandonar el escenario. A punto de salir, su sombra se proyecta sobre el fondo, semejando la negra silueta de una mujer... Y sale. Ronroneo. Cae el telón.) 
Tal como se puede comprobar, la micropieza de Zurro es un verdadero chispazo insólito, un flash de suceso anecdótico, apenas un parpadeo de burla (al espectador). Resulta una micropieza de contenido polisémico, cuya chanza sorpresiva revierte sobre el espectador (lector), provocada por el absurdo insustancial de lo escenificado, tras lo cual, probablemente, se pensará en la posible interpretación de lo visto (o leído), cuyo significado final (toda ella es un final) resulta ambiguo y abierto. Por otro lado, «La gata» resulta altamente simbólica y metafórica, mínimas acciones evocadoras de mensajes subliminales. En ambas micropiezas los personajes sirven para sostener o proyectar la ocurrencia anecdótica o la idea transmitida por las acciones escenificadas. Respecto a los propios microtextos, en ambos casos se refleja bien el código genético de lo dramático, sin resultar inestable hacia otros fenómenos. En este sentido, por ejemplo, el texto didascálico de «La gata» no llega a caer en lo poemático, pues se advierte en él su funcionalidad en torno al interés dramático por señalar los personajes, así como por indicar la escena y señalar las acciones representables y transmisoras de una idea evocada, pero representable dramáticamente.

En el microteatro el título textual suele tener mayor relevancia o importancia que en el teatro en general, pero sin llegar al extremo de lo que ocurre en la microficción, ya que la microficción solo reposa sobre el texto mismo (y, por tanto, suele explotar su título al máximo, llegando incluso a dejar de ser paratexto para ser texto), mientras que el texto del (micro-)teatro se proyecta hacia su escenificación o representación. No obstante, si destacamos en el (micro-)teatro un índice puramente (para-)textual como es el título, se debe a que, en general, el público que ve una obra de teatro suele, al menos, conocer su título. Ahora bien, una importancia semántica o significativa mayúscula del título para la interpretación fundamental de la micropieza dramática podría denotar una inestabilidad o deslizamiento hacia otro fenómeno literario puramente textual, tal como, por ejemplo, la microficción o microrrelato.

Por otro lado, el microteatro, debido a su hiperbrevedad, suele apoyarse en cierta intertextualidad o transtextualidad, ya que estos recursos permiten encuadrar mejor personajes o escenas. En este sentido, puede también recurrir a tópicos, clichés culturales, etc., apelando a la enciclopedia general del espectador/lector, tal y como parece ocurrir, por ejemplo, en «La gata», cuya micropieza evoca reminiscencias o alusiones ecoicas de la mujer fatal (cliché muy cinematográfico). En general, el microteatro suele jugar con representaciones estereotipadas, alusiones culturales, guiños de todo tipo, etc. Asimismo, resulta frecuente el recurso de la metaficción dramática o metateatro (incluso a veces rompiendo la cuarta pared). No faltan tampoco diversas clases de ambigüedad semántica, algunas de estas provocadas por un final sorpresivo, abrupto o enigmático, tal como sucede en «La pluma». También abunda en el microteatro diferentes tipos de humor e ironía: paródica, sarcástica, humor negro, absurdo, etc. No obstante, no todo microteatro recurre a la comicidad y/o a la ironía. En torno a todo esto, transcribimos otros dos ejemplos de microteatro bien distintos entre sí; el primero es de Antonio Álamo; el otro, de Pascual-Antonio Beño Galiana: 


\section{LA ÚLTIMA VEZ}

A, fumando.

A. Esta es la última vez que fumo un cigarrillo. (Lo apaga. Saca una pipa, la enciende y fuma.) Esta es la última vez que fumo en pipa. (Tira la pipa. Saca un puro, lo huele, lo chupa, lo enciende.) Esta es la última vez que fumo un puro. (Lo rompe y lo tira. Saca un papel de plata y un rulo. Aspira.) Esta es la última vez que me fumo un chino. (Se deshace de él. Pausa larga.) ¿Desesperanzados, eh? Esta es la última vez que hablo, y mi frase es... «Esta es la última vez que respiro». (Coge aire, lo sostiene hasta el límite, vemos como se asfixia. Colapso final.)

(Álamo, 2006a: 2)

\section{EL FIN DEL MUNDO}

Recorrerán el escenario UN RAPSODA y EL CORO. El CORO estará formado por tres o cuatro actores. Actuarán como a cámara lenta y de una forma ceremoniosa y harán tres paradas en las que se recitarán los versos.

RAPSODA. Él fue, estuvo, existió, y ahora es tan solo, bajo la tierra madre nuevamente, materia corrompida. Aún es recuerdo apenas, pero pronto será menos que nada.

CORO. Pero nosotros estamos vivos.

RAPSODA. Y nada quedará de aquella carne que cruzó por el tiempo tan altiva. Y los propios gusanos destructores volverán a la nada; más, con todo, disfrutad de la fiesta del instante.

CORO. Porque nosotros estamos vivos.

RAPSODA. Auténtica verdad del «carpe diem». Apurad el instante de juventud hermosa; anclaos intensamente en el ahora, por furor, pues sabéis que todo acabará.

CORO. Porque nosotros estamos vivos.

Salen del escenario sin variar sus actitudes.

(Beño Galiana, 2006a: 9)

En ambos microdramas se comprueba cierto humor negro, pero mientras que en el primero resulta sarcástico, en el segundo es literalmente fúnebre, clásico y elevado, despojado de una burla sarcástica. Asimismo, si en el segundo vemos esquemas dramáticos del teatro clásico (personaje y coro, lenguaje recitado, tono elevado, capsula dramática atemporal y universal), en el primero, en cambio, sucede todo lo contrario: instalado en la actualidad social, con lenguaje coloquial y argot de la calle («rulo», «chino») y con un personaje (representativo del caos) inestable, inconsciente e indeciso, que termina suicidándose. Su desesperación, por medio de sus acciones repetitivas y contradictorias, es trasladada y preguntada al público (rompiendo así, fugaz e irónicamente, la cuarta pared). Antítesis todo ello de lo escenificado en el segundo microdrama, el cual es un revestimiento dramático para transmitir mejor el tópico esencial y meditativo del carpe diem. Finalmente, los personajes no tienen siquiera nombres comunes, ya que no interesa su caracterización, sino la transmisión de un estado anímico o de un concepto.

Destacamos ahora otras dos micropiezas en donde hablan dos o más personajes, tal y como sucede, por ejemplo, en la de Paco Benítez, titulada «Al teléfono», y en donde aparecerán en escena hasta cuatro personajes, y en la titulada «Ella y la otra», de José Luis Miranda, en donde aparecen dos. Así pues, transcribimos estas dos obritas de microteatro: 


\section{AL TELÉFONO}

PACO habla por teléfono con ALFONSO

PACO. ...no, no... No tengo ninguna obra... No, ninguna, nada de nada... No, ni para un minuto... Es que no tengo ningún argumento para la obra... Ah, pues eso es una cosa que me da que pensar, pensamiento funerario, de aire turiferario de algo muy literario... No, no tengo ninguna idea... Bueno, se me ocurre una idea... Lo que hace falta es una mujer. Una mujer. En toda obra hace falta una mujer... (Entra PEPITA, gordísima y feísima.) ¿Que si se desnuda?...

PEPITA. ¿Me desnudo?

PACO. No, no, no... no se tiene que desnudar... si se tiene que desnudar, yo quisiera otro material... digamos más... mercadotécnico... estético... metrotécnico... más tipo... (Y entra PEPITA 2, una mujer escultural y bellísima.) Sí, me encanta.

PEPITA 2. Que me han violado. Que me han violado. Que me han violado.

PACO. Sí, eso grita... ¿Qué quién? ¿Qué quién la ha violado?... No, yo no he sido, ¿has sido tú?... Reconócelo ¿has sido tú?... bueno, bueno... sí, sí, con esa entrada y esos gritos, es necesario...

PEPITA 2. Un juez. Un juez. (Entra un juez.)

JUEZ. ¿Qué es lo que hay aquí?

PEPITA 2. Un delito, un delito, a mí me han violado.

JUEZ. ¿Pero quién te ha violado?

PEPITA 2. Y yo no lo sé porque estaba muy oscuro. Y yo no lo sé porque estaba muy oscuro.

JUEZ. ¿A qué hora fue?

PEPITA 2. A las doce en punto de la noche.

PACO. ¿Y dónde estabas tú Alfonso a las doce en punto de la noche?... ¿Leyendo una obra de teatro de Paco Benitez? Ya. Y yo me lo creo... ¿Y yo? ¿Qué dónde estaba yo?... Pues yo estaba acostándome con el juez. ¿Qué? ¿Qué que te parece? ¿A que es una buena idea?... Sí, seguro que da juego... La desarrollo, la escribo y te la leo por teléfono... vale. Buenas noches.

(Benítez, 2006a: 8)

\section{ELLA Y LA OTRA}

ELLA. No te hagas la distraída. Te conozco madre, y te conozco tanto que me siento Edipo. Creo que me he acostado contigo. Por ignorancia. Y hemos tenido hijos sin saberlo.

LA OTRA. (Probándose un traje y mirándose en un espejo.) Ay, hija. Este traje no me queda bien. ¿Tú no lo ves? Y estoy segura de que no he engordado.

ELLA. Ocurrió hace mucho, mucho tiempo. Antes de Eva. Quizá fue en la época de Lilith. O antes. Creo que me acosté contigo, madre, antes de todos los tiempos. Sin saberlo, sin saber que era Edipo. Y desde entonces han ido naciendo monstruos. Son nuestros hijos.

LA OTRA. Me respinga. El traje me respinga. ¿No lo ves?

ELLA. No puedo engañarte más, madre, soy Edipo. Hay errores sin perdón. Errores sin culpa, pero errores que crecen. Y tú debes saberlo. Tienes que saberlo, madre.

LA OTRA. (Se quita furiosamente la peluca. Es un hombre.) Mira, niña, que yo no soy tu madre.

ELLA. ¡Qué soledad!

(Miranda, 2006a: 39) 
En la de Paco Benítez, según vemos, la ironía y el humor están bien presentes, pero la comicidad irónica contenida en la micropieza es toda ella de índole metateatral: una prolongada metaficción sutil en la que, sin embargo, no se rompe la cuarta pared. Todos los guiños giran en torno a esta idea metateatral escenificada, en donde el protagonista, que es el propio autor citado en la misma obra, es decir Paco Benítez, habla con Alfonso (Zurro) sobre la problemática creativa de tal obra de 1 minuto y sobre las posibles ideas argumentales, las cuales se van corporizando o visualizando a través de los personajes que entran en escena (Pepita 1, 2 y Juez), todo muy «turiferario de algo muy literario», pero efectivamente dramatizado. Por otro lado, en «Ella y la otra» abundan las referencias intertextuales literarias a personajes de la mitología y bíblicos (Edipo, Lilith y Eva), así como el final sorpresivo y chistoso de la micropieza resulta un guiño transtextual al final célebre del filme de Billy Wilder: Con faldas y a lo loco (Some Like It Hot, 1959). Aquí la micropieza es un proyectil dramático lanzado para su efecto final: una especie de chiste travestido bien dramatizado.

En esta ocasión, vamos a seleccionar dos monólogos microdramáticos muy diferentes entre sí por sus respectivos tratamientos de la ironía sobre un mismo tema. Pasamos a transcribir, pues, uno de Jesús Campos, titulado «Es solo una enfermedad», y otro de Francisco Nieva, titulado «Redoble de tambor (drama de un minuto)»:

\section{ES SOLO UNA ENFERMEDAD}

SACERDOTE. Cuando supe que en San Francisco había una enfermedad que sólo mataba a los maricones, pensé: alabado sea Dios, por fin vamos a acabar con esa plaga de degenerados. No está bien alegrarse de una cosa así, lo sé, pero me alegré. Por una vez los males de este mundo no eran arbitrarios, sino que castigaban, como una maldición, la insolencia de los pecadores. Sodoma y Gomorra volvían de nuevo a sucumbir bajo una lluvia de fuego. iLa ira de Dios! Al fin la ira de Dios fulminaba a quienes atentaban contra las leyes de la naturaleza.

Pero cuando ayer fui a recoger el resultado de los análisis y supe que era seropositivo -yo, seropositivo; yo, que sólo voy con mujeres-, sentí que me convertía en estatua de sal.

(Campos, 2006a: 11)

\section{$*$}

REDOBLE DE TAMBOR

(drama de un minuto)

[Aparece un actor vestido de payaso, llevando en bandolera un tambor.]

¡Público, concurrencia, amigos que aquí estáis! Antes de comenzar nuestra función, me obligo a daros una noticia. [Redoble de tambor.]

$E l$ «SIDA», la gran plaga de nuestro tiempo, pide colaboración y ayuda de toda la ciudadanía, desde los más diversos puntos de expresión. Y así lo pide desde el teatro y el espectáculo, lo pide incluso vestido de «clown». [Transición.]

También hay payasos con «sida» y actores y músicos y autores y técnicos y... iAtención! [Redoble de tambor.] También hay público con «sida». [Transición.]

Y así, advertimos «al respetable» que también el payaso llora por todos. [Deja caer el tambor y se va aproximando al público.]

Mírenme llorar. Acérquense, no teman, comprueben por ustedes mismo que lloro de verdad.

(Nieva, 2006b: 220) 
Como se puede observar, ambos microdramas comparten el monólogo y la crítica social respecto a la actitud y respuesta generalizada ante el sida (ya sea por hipocresía, por rechazo, por ignorancia, por temor al contagio, etc.), cuya enfermedad ha sido proscrita socialmente como un tema tabú. Ahora bien, dicho esto, ambas micropiezas dramáticas resultan muy diferentes. En la de Jesús Campos, por ejemplo, se percibe su comicidad de ironía mordaz, así como su parodia sobre el personaje tipo, el sacerdote, representante aquí de la estulticia intolerante y fundamentalista y de la gran hipocresía. En cambio, en el microdrama de Francisco Nieva la ironía no resulta cómica o humorística, sino seria y metateatral: alusiones metadiscursivas o metaficcionales al teatro (escenario, público, etc.), referencias al y del propio personaje (prototipo de la comedia), exhortación muy actoral, tanto en su declamación como en sus actos de redoble de tambor, por el reconocimiento de la ruptura de la cuarta pared y del verdadero llanto... deconstruido. En definitiva, buen ejemplo de microdrama y de microteatro metaficcional, cuya indagación metateatral resulta bien distinta a la de Paco Benítez. Por otro lado, respecto al código del género dramático en ambas micropiezas, podemos señalar que en la de Nieva resulta evidente, mientras que en la de Campos, si no fuera por el claro estilo del monólogo en proyección funcional perceptible hacia el público, resultaría problemática para clasificarla como tal microdrama, pero su enfoque discursivo hacia el público nos resulta reconocible como fenómeno del microteatro.

Ofrecemos ahora dos ejemplos más, ambos comparten una misma temática de crítica contra la guerra y ambos carecen de comicidad o humor. El primero de ellos es de José Luis Alonso de Santos, titulado «De mayor quiero ser bomba», el cual, tal y como se verá, es otro buen ejemplo del fenómeno del microteatro actual. El segundo, titulado «Y Johnny cogió su fusil», de Alfredo Castellón, nos servirá como ejemplo de deslizamiento de fronteras o límites borrosos con el fenómeno de la microficción. Así pues, son los dos siguientes:

\section{DE MAYOR QUIERO SER BOMBA}

Una madre abrazada a sus dos hijos, de unos diez años. Se oyen, y ven, las explosiones de un bombardeo.

NIÑO: ¿Por qué nos tiran bombas?

MADRE: No lo sé, hijo. Dicen que es por nuestro bien...

Pausa

NINAA: ¿Nos van a matar, madre?

MADRE: Si nos cae una bomba, sí, hija.

Pausa

NIÑO: ¿Qué les hemos hecho, madre, para que quieren matarnos?

MADRE: Nada. No les hemos hecho nada, hijos. Ni siquiera nos conocen.

NIÑA: ¿Entonces por qué quieren matarnos?

MADRE: No lo sé, hija.

NIÑO: ¿Y nos va a doler, madre?

MADRE: Estaremos juntos los tres, muy juntos, abrazados, y no nos dolerá.

NIÑO: Tengo miedo, madre.

NIÑA: Yo también tengo mucho miedo.

MADRE: Todos tenemos miedo.

Pausa

NIÑA: No lo entiendo, madre, no lo entiendo. 
MADRE: Yo tampoco, hija.

Pausa

NIÑO: Madre, si no me matan, cuando sea mayor ya sé lo que quiero ser. Quiero ser bomba, madre, para ir a matarlos a ellos y a sus hijos. Quiero ser bomba, madre, quiero ser bomba.

(Alonso de Santos, 2003: 13-14)

$*$

\section{Y JOHNNY COGIÓ SU FUSIL}

ACTO I

Johnny tenía 18 años y cogió su fusil y se fue a la guerra, bueno, la realidad es que el fusil se lo dio su presidente.

\section{ACTO II}

Cuando regresó de la guerra veía mal, apenas podía respirar, ni comer, tan sólo entendía si le hablaban por señas, una piltrafa humana, esa es la verdad.

Al final, perdió completamente la vista y le preguntó un día a su madre que lo amaba entrañablemente.

JOHNNY: Madre, ¿dónde está la luz?

MADRE: La luz está en llamas, hijo mío.

JOHNNY: ¿Y cuando se apagarán?

MADRE: Cuando se apague el hombre, que es el que la provocó.

JOHNNY: Triste.

MADRE: Triste, sí muy triste. (Pausa.)

\section{ACTO III}

JOHNNY: Madre, me acuerdo mucho de los muertos.

MADRE: Es normal hijo mío, ellos tuvieron más suerte que tú.

(Castellón, 2003: 57-58)

Respecto al de Alonso de Santos, todo en él denota bien el código del género dramático: las acotaciones, los diálogos entre la madre y sus dos hijos (niño y niña), la selección del cuadro dramático, el desarrollo y conflicto a través de tales diálogo, etc. En el final se aprecia bien la ironía sutil y crítica sobre el tema, cuya violencia (guerra, odio, injusticia, etc.) engendrará más violencia (guerra, odio, injusticia, etc.). Aquí la poesía dramática emana del propio desarrollo configurador del cuadro dramático y de lo representado y escenificado, cuya autosuficiencia dramática se proyecta sobre su esencia misma, y no sobre apoyaturas de la textualidad prosística ajenas a ese rearme de creación de la poeticidad dramática en sí (en el teatro más extenso hay espacio para perder, alterar o mutar esencialidades dramáticas, en el microteatro, en cambio, no ocurre lo mismo). En definitiva, otro buen ejemplo de microteatro sintético, cuya reducción mínima textual, tal como señalaba Quiles, no supone ausencia de la esencia del drama.

Ahora bien, en la micropieza de Alfredo Castellón, vemos cómo las acotaciones (o didascalias) revierten sobre el texto mismo, se explayan en él y son muy literarias y narrativas, de cierta intencionalidad ficcional narrativizadora y no dramatizadora, las cuales ca- 
recen de función esencial dramática, desinteresadas u olvidadas ya de la creación dramática, de la representación sustancial del cuadro dramático (a no ser que se formulen como voz en off narradora de ellas, pero no se indica esto siquiera). Asimismo, la selección de «Actos» para emplear acotaciones narrativas y literarias sobre una historia, ajenas al rearme dramático, se proyecta y sustenta en la lectura textual, en donde aquí ya todo el conjunto adquiere una fuerte carga poética y literaria narrativas. Por otra parte, la escena dramática es mínima y muy poética, cuya representación corta perdería parte de la efectividad poética emanada de las acotaciones y del conjunto mismo. No obstante, contrarresta algo todo esto el hecho de que la micropieza se apoye completamente en lo intertextual, tanto en la alusión directa desde el título mismo como en la escena recreada e inspirada en el filme antibelicista titulado Johnny got his gun (1971), dirigida por Dalton Trumbo, quien escribió también el guion basado en su propia novela del mismo título y publicada en 1939. En este sentido, gracias al apoyo intertextual, el espectador puede contextualizarlo todo al instante y captar rápidamente la poeticidad de la escena dramatizada, ampliando y completando mejor todo lo aludido y elidido (en las acotaciones). En este caso, la escena dramatizada sería suficiente como para transmitir esa poeticidad dramática total que se consigue en la combinación con las acotaciones narrativas de Castellón. Así pues, resulta entonces un ejemplo de microteatro altamente intertextual y poético, algo desplazado u oscilante hacia la microficción.

Vamos a ofrecer un último ejemplo de microteatro metaficcional titulado, precisamente, «El teatro», de Juan Cobos Wilkins. Al igual que en «La gata», esta micropieza es una didascalia textual, pero no presenta problemas ni se desliza hacia otros fenómenos literarios, tal como acontece en las acotaciones de Castellón. Finalizamos, pues, con este ejemplo de microteatro metateatral, bien distinto de los de Benítez y Nieva, tal y como se verá a continuación:

\section{EL TEATRO}

En escena, una butaca igual a las de la sala. Sentado en ella está el ESPECTADOR. Ante él, de pie, el ACTOR.

El ACTOR se aproxima al ESPECTADOR. Como reconociéndole, merodea, da una vuelta en torno a su asiento. Por detrás, desde la espalda le susurra algo al oído y el ESPECTADOR comienza a reír. Rápidamente vuelve a susurrar, pero esta vez en el otro oído, y ahora el ESPECTA$D O R$ rompe en sollozos.

El ACTOR coloca su mano sobre el pecho del ESPECTADOR, en el lugar del corazón, y el cesa de llorar se levanta. ACTOR y ESPECTADOR intercambian sus lugares: ahora es éste quien está de pie y aquél sentado.

Ambos se zarandean por las solapas, sacan a la vez sendas pistolas y apuntan uno al otro... disparan simultáneamente. De los cañones: sale confeti de colores o una flor...

Los dos en pie y frente a frente se dedican una mutua reverencia. Luego hacen un gesto con los brazos como mostrando y abarcando el público, las butacas, el escenario, todo el recinto. Entonces, la escena se llena de pequeñas lucecitas plateadas que semejan estrellas $y$, de fondo, se escucha una forma perfectamente reconocible- el ruido del mar olas rompiendo.

Tras unos segundos, silencio y oscuridad total. ACTOR y ESPECTADOR habrán hecho, mientras, mutis. Escena vacía. Y una voz dice:

-Señoras, señores, el Teatro.

(Cobos Wilkins, 2006a: 13) 


\section{AL OTRO LADO DEL ESPEJO: LA MICROFICCIÓN DIALÓGICA Y DE APARIENCIA TEXTUAL DRAMÁTICA}

La microficción (o microrrelato) se ha revelado como un fenómeno literario proteico, pues suele adoptar infinidad de formatos, categorías y géneros ajenos con cuyas múltiples formas se metamorfosea, mayormente para parodiar, ironizar, explorar o explotar recursos literarios a partir de intenciones narrativizadoras de producción ficcional, y, generalmente, con particulares intereses creacionales sorpresivos y desautomatizadores de lo establecido en relación con lo literario. Asimismo, junto al carácter proteico se suelen integrar otros recursos de apelación y completitud receptiva, tales como aquellos de índole intertextual, ya que facilitan la reducción textual y, al mismo tiempo, favorecen la narrativización desencadenada en la elipsis que gobierna sobre la microficción.

Dicho esto, y antes de recorrer algunos ejemplos de microficciones dialógicas y de apropiaciones de elementos textuales dramáticos, vamos a aportar aquí una mínima definición sobre el fenómeno literario de la microficción contemporánea, de tal forma que podamos comprender mejor dicho fenómeno microficcional, así como sus casos mayores de indistinciones proteicas respecto al otro fenómeno estudiado del microteatro actual (y viceversa).

A diferencia de ciertos postulados más narrativistas sobre el fenómeno del microrrelato, los cuales suelen concebir la narratividad del microrrelato a partir de su textualidad narrativa, nosotros, en cambio, concebimos el fenómeno genérico de la microficción contemporánea (microrrelato, minificción o minicuento) como un microtexto literario autónomo de ficcionalidad narrativizadora gobernada por la elipsis. Es decir, el común denominador genérico de este corpus microtextual estaría en su carácter ficcional de índole narrativizador o narrabilizador literario, y no en que el texto sea o deba ser narrativo, ya que algunos de los necesarios elementos de la secuencia narrativa textual pueden estar elididos, incluso hay casos en los que la secuencia textual narrativa está completamente elidida. Solo piénsese, entre otros tantos casos de microficción narrativa elíptica, en los siguientes célebres ejemplos — por este orden— de Juan Pedro Aparicio, Guillermo Samperio y Sergio Golwartz:

$\begin{array}{lr}\underset{\text { LUIS XIV }}{\text { Yo }} & \text { EL FANTASMA } \\ & \text { Dios }\end{array}$

Asimismo, la narratividad prosística de la microficción puede conllevar cierta hibridez o mixtura de elementos no narrativos, tal como ya señalara Dolores Koch (1981) respecto a su específica distinción del micro-relato frente al minicuento.

Así pues, aquel denominador común es lo que nos permite advertir e identificar que estamos ante una microficción cuyo aspecto formal ha adoptado, proteicamente, otras formas o géneros literarios (antiguos o modernos) diversos, por ejemplo. En este sentido, advertimos que tales formas o géneros adoptados son simulacros formales por su carácter ajeno, distinto, desviado, disfuncional o espurio al estipulado o común en tales formas o géneros explotados en la microficción, cuyo fenómeno nos revela un carácter ficcional narrativizador literario sobre la función caracterizadora de otros géneros, di- 
gamos, más propiamente líricos o poéticos, especulativos o ensayísticos, o dramáticos, por ejemplo. En el caso de las categorías/formas cortas arcaicas y tradicionales (especialmente micronarrativas), el fenómeno microficcional también adopta sus formas, pero pervierte o anula su función caracterizadora didáctica o moral, parodiándolas generalmente.

En este sentido, toda producción microtextual contemporánea que presente tales características e intenciones literarias microficcionales podrá ser, en principio, entendida como microficción. Por otro lado, los ejemplos de microteatro que hemos visto podrían ser contemplados como microficción si los descontextualizáramos totalmente y prescindiéramos de sus auténticas intenciones dramáticas de escenificación, imaginándonos, asimismo, que jamás se hubieran escenificado ni que se pudieran escenificar este tipo de microtextos dramáticos, y que, por tanto, fueran solo formulaciones experimentales literarias puramente textuales y de lectura; es decir, ficciones de obras de teatro... Es por esto que nosotros distinguimos aquellos fenómenos como microTEATRO, pues, efectivamente, tales micro-obras dramáticas, con sus propios códigos funcionales del género, revelan su composición de acuerdo a la esencia dramática en relación con su escenificación, algo ajeno por completo a la naturaleza puramente textual-literaria de la microficción, cuyo fenómeno se apropia literariamente de tales elementos textuales dramáticos para explotar y explorar sus propios fines y metas de ficcionalidad narrativizadora, tal como veremos después.

Apuntado todo esto, vamos adentrarnos en las microficciones dialógicas y de mayores elementos dramáticos, las cuales estudia Juan Armando Epple en relación «al teatro virtual como estrategia narrativa en textos minificcionales» (2010: 133), señalando al respecto lo siguiente:

El llamado «teatro virtual», heredero de los antiguos diálogos filosóficos griegos y del teatro de ideas del siglo xvii, es en rigor una situación narrativa diseñada en forma de diálogo teatral. Nos da la ilusión de estar frente a una escena de espectáculo teatral pero sabiendo que estamos experimentando una lectura privada de la situación narrada. Sus funciones literarias son crear un sentido de inmediatez del suceso narrado, acentuar el carácter dramático de ese suceso o el conflicto básico y situar al lector en un plano de distanciamiento crítico, al estilo brechtiano, o como un voyeur privilegiado. (Epple, 2010: 133)

En torno a esta modalidad narrativa de teatro virtual, Epple destaca como perfecto exponente las Historias mínimas de Javier Tomeo, «un conjunto de minificciones en forma de escenas teatrales» (2010: 133). Además de transcribir dos de ellas y comentarlas, recogerá también tres microficciones dialógicas y una cuarta más teatralizada.

En nuestro caso, vamos a ofrecer ejemplos divididos en dos tipos: las microficciones de diálogos o dialógicas, las cuales no resultan tan problemáticas, y aquellas otras microficciones más teatralizadas o con mayores apropiaciones de elementos textuales dramáticos, tal y como, por ejemplo, sucede ya con las apuntadas microficciones escenificadas de Tomeo. Dejaremos los ejemplos de estas últimas para el final, ya que son las que pueden tener más problemas por su mayor semejanza formal con el microteatro. 
Así pues, como ejemplo bien narrativo de un diálogo dramatizado filosófico (metafísico y metadiscursivo), comenzamos exponiendo una clásica microficción incluida en $\mathrm{El}$ hacedor (1960), de Jorge Luis Borges:

\section{DIÁLOGO SOBRE UN DIÁLOGO}

A.-Distraídos en razonar la inmortalidad, habíamos dejado que anocheciera sin encender la lámpara. No nos veíamos las caras. Con indiferencia y una dulzura más convincentes que el fervor, la voz de Macedonio Fernández repetía que el alma es inmortal. Me aseguraba que la muerte del cuerpo es del todo insignificante y que morirse tiene que ser el hecho más nulo que puede sucederle a un hombre. Yo jugaba con la navaja de Macedonio; la abría y la cerraba. Un acordeón vecino despachaba infinitamente la Cumparsita, esa pamplina consternada que les gusta a muchas personas, porque les mintieron que es vieja... Yo le propuse a Macedonio que nos suicidáramos, para discutir sin estorbo.

Z (burlón). - Pero sospecho que al final no se resolvieron.

A (ya en plena mística). - Francamente no recuerdo si esa noche nos suicidamos.

(Borges, 1975: 19-20)

Seleccionamos ahora una microficción de William Ospina, cuyo simple diálogo mínimo no ofrece tampoco confusión alguna, ya que resulta el típico de la narración:

\section{AMENAZAS}

-Te devoraré - dijo la pantera.

- Peor para ti - dijo la espada.

(Cf. Obligado, 2001: 167)

Finalmente, transcribimos dos microficciones dialógicas sin marcas ni apuntes. La primera —una entrevista muy metaficcional- es de Juan Carlos García Rey, y la segunda — un interrogatorio muy intertextual— es de José Cardona López:

\section{ÚLTIMO CUENTO}

-En sus cuentos breves el tema de la muerte suele aparecer con cierta frecuencia, ¿a qué se debe?

-No es un tema privativo de mis cuentos, habrá notado que en la vida también suele aparecer con cierta frecuencia.

- ¿No teme jugar con la muerte?

- Soy un escritor temerario.

- ¿Qué está escribiendo ahora?

-Un cuento trivial: el escritor que dialoga con la Muerte y la muy pícara lo sorprende en la mitad de una palabra.

- ¿Cuál palabra?

-No sé, pero seguramente le va a faltar la última sílaba y el cuento quedará inconclu

(Cf. Obligado, 2009: 118) 
QUE TRATA DE LA INDAGATORIA AL INGENIOSO CABALLERO DON MIGUEL

- ¿Lugar?

-De la Mancha.

- ¿Nombre?

-No quiero acordarme.

- ¿Por qué?

-No sé. No quiero.

- ¿Apellido?

-Hidalgo.

- ¿De cuáles?

-De los de lanza en astillero, adarga antigua, rocín flaco y galgo corredor...

- Gracias, eso es todo.

_... una olla de algo más vaca que carnero, salpicón las más noches...

- ¡Basta! ¡Basta!

—... algún palomino de añadidura los domingos...

— ¡Basta! ¡BAS-TA! Que siga el próximo caballero.

(Cf. Epple, 2010: 136)

Pasamos ahora a la microficción más proteica por sus mayores apropiaciones de elementos textuales dramáticos (diálogos con personajes apuntados como en las obras dramáticas, uso de acotaciones o didascalias, etc.). Pondremos tres ejemplos, los dos últimos más proteicos que el primero, pero todos ellos buenos ejemplos para comprobar cómo la microficción explota y aprovecha formas y marcas características de otros géneros, en este caso del género dramático, para su propio beneficio e interés ficcional narrativizador. Así pues, la primera se titula «La histérica», incluida en el libro de microficciones Tapioca Inn: mansión para fantasmas (1952), de Francisco Tario, cuyo final evidencia ya su ficcionalidad narrativa, tal y como se verá a continuación:

\section{LA HISTÉRICA}

A pleno día.

El psiquiatra:-Desnúdese.

La histérica: -iImposible!

El psiquiatra: - Me desnudaré yo, entonces.

La histérica: - Como usted guste.

(El psiquiatra se desnuda).

El psiquiatra: ¿¿Ve usted qué sencillo?

La histérica: - ¡Asombroso! Probaré yo a hacerlo.

(Se desnuda. Suena el teléfono).

El psiquiatra: -Sí, señor, inmediatamente. (A la paciente) Le habla su marido.

(La histérica toma el audífono).

La histérica: —¿Eres tú, queridito?

La voz lejana: -Soy yo, ¿no te da vergüenza?

(La histérica se mira).

- ¿Ni siquiera pensaste en los niños?

(Pausa).

-Y por si fuera poco, ¿no sientes frío? 
La histérica: -Perdóname; no siento frío. ¿Me perdonas?

La voz lejana (tras un silencio): - Está bien, te perdono, ;Que no vuelva a repetirse!

(La histérica deja el audífono y se vuelve. Da un grito, cubriéndose. Está en una zapatería).

(Cf. Valadés, 1970: 181-182)

La siguiente microficción, titulada «Comunicación», es de Pablo Urbanyi, y en la cual se revela con la acotación primera y abierta su narratividad, así como en la nota explicativa del comienzo, según la transcripción de David Lagmanovich (2005) en La otra mirada. Antología del microrrelato hispánico, tal y como se podrá leer a continuación:

\section{COMUNICACIÓN}

Tomado y teatralizado de un dibujo anónimo.

Él y Ella. Los encontramos sentados en los dos extremos de un sofá de tres plazas. Él la observa con un poco de temor. Por fin se anima a hablar:

Él: Parece que estás de mal humor, ¿qué te pasa?

Ella: No me pasa nada. Y te ruego que no hagas suposiciones sobre mí.

Breve pausa.

Él: ¿Es por algo que dije?

Ella: No.

Él: ¿Es por algo que no dije?

Ella: No.

Él: ¿Es por algo que hice?

Ella: No.

Él: ¿Es por algo que no hice?

Ella: No.

Una pausa más larga. Toma aire y remarcando con claridad las palabras:

Él: ¿Es por algo que yo dije casualmente en relación a algo que hice y que no debía haber hecho ni dicho, o por lo menos debería haberlo hecho y dicho de otra manera y tomando en cuenta tus sentimientos?

Ella: Algo así. Pero basta, no insistas.

(Cf. Lagmanovich, 2005: 296)

Finalmente, vamos a concluir con la microficción dramática IV $^{12}$ de la obra señalada de Javier Tomeo: Historias mínimas (Barcelona, Mondadori, 1988 ${ }^{13}$ ); cuyo libro ha sido muy citado, estudiado y analizado en profundidad desde la teoría del microrrelato o micro/minificción hispánica, especialmente por Andres-Suárez (cf. 2010: 194-219). Por otra parte, resulta particular el caso de las Historias mínimas de Tomeo, ya que estas microficciones, por

12 Recogida también por Lagmanovich (2005: 173), Epple (2010: 133) y Andres-Suárez (2010: 211-212), de quien recogemos la microficción de Tomeo. Por otro lado, aunque esta microficción IV, tal como sucede en las dos anteriores que hemos transcrito, reincide en cierto conflicto hombre-mujer, esto no significa que no se dé una enorme y variadísima temática en la microficción (dialógica); pero la hemos seleccionado, al igual que aquellas dos, por resultar representativos ejemplos proteicos en lo dramático.

${ }^{13}$ Esta primera edición, tal como apunta Andres-Suárez, «consta de cuarenta y dos microtextos y la segunda (Barcelona, Anagrama, 1996) de cuarenta y cuatro» (2010: 195). 
sus cualidades dramáticas, han sido llevadas a los escenarios y estrenadas como verdaderas obritas de teatro, lo que tampoco resulta muy extraño, pues tales microficciones teatralizadas resuenan un tanto al teatro del absurdo (Beckett, Ionesco, etc.), entroncado también con Buñuel y Arrabal..., incluso se asemeja al teatro disparatado o humorístico de la posguerra española; además del particular universo literario del escritor español muy afín a lo kafkiano, etc. No obstante, la narrativa de Tomeo no deja de ser singular en cierto modo, pues siendo un perfecto narrador, aunque conocedor de las técnicas teatrales, sus obras narrativas gustan de llevarse a los escenarios y al cine; seguramente sea esto porque sus modelos son situaciones dramáticas, inclinado, digamos, por una narrativa de la dramática. Dicho esto, pasamos, pues, a transcribir la citada microficción teatralizada de Javier Tomeo:

IV

En el centro del escenario, sentados al pie de un árbol que ha perdido ya todas las hojas, vemos ahora a un HOMBRE y a una MUJER.

HOMBRE. (Mirando al frente, sin volverse hacia la mujer.) Oye.

MUJER. Qué.

HOMBRE. Dame tu ojo izquierdo.

Pausa. La MUJER se desenrosca su ojo de cristal y se lo alarga al compañero.

HOMBRE. (Recogiendo el ojo, que se guarda en el bolsillo cerillero de la chaqueta.) Ya sabes que te prefiero tuerta, Manuela.

Silencio. El HOMBRE y la MUJER continúan inmóviles, indiferentes al coro de risotadas que se ha levantado en el patio de butacas.

Sobre su narratividad en marcadores dramáticos, Andrés-Suárez apunta lo siguiente:

Al inicio, el narrador circunscribe el espacio («en el centro del escenario, sentados al pie de un árbol...»), mas a continuación abandona su papel de demiurgo para incluirse entre los espectadores: «vemos ahora a un hombre y a una mujer». Después, señala la presencia activa del público y sus reacciones: coro de risotadas que se ha levantado en... (2010: 212)

Antes de concluir este apartado, queremos señalar un particular fenómeno producido dentro del ámbito de la difusión de la microficción hispánica, desde los años cuarenta del siglo xx, aproximadamente, hasta la actualidad. Nos referimos aquí a la singular producción cocreadora de resignificación en microficciones a través de operaciones de recortes hiperbreves de textos mayores y titulaciones ajenas, entre otras operaciones diversas. En este sentido, destacamos la labor pionera de Borges (en colaboración con Bioy) en torno a este tipo de operaciones de gran influencia para la ulterior difusión y proyección genérica de la microficción hispánica. Respecto a todo esto, pondremos dos ejemplos de tales operaciones de titulación y recorte significativo y transmisor de «Lo esencial de lo narrativo» (Borges y Bioy, 1955: 9) en obras de todo tipo y género. Ambos recortes titulados servirán para mostrar todo esto que estamos señalando, los cuales se asemejan a la específica producción de microficciones proteicas, de índole dialógica o dramática, ya apuntada. Estos recortes titulados, de resignificación en microficciones autónomas, proceden de dos obras célebres del siglo Xıx: una obra dramática española (Don Juan Tenorio de José Zorrilla) y una novela inglesa (Alicia a través del espejo de Lewis Carroll). Asimismo, los autores de tales cocrea- 
ciones fueron Borges y Bioy, aunque la de Carroll puede que la realizara Edmundo Valadés, la cual apareció incluida en su antología de 1970. Así pues, transcribimos estas dos microficciones dialógicas cocreadas por los citados antólogos:

\section{EL ESPECTADOR}

DON JUAN: - ¿Y aquel entierro que pasa?

ESTATUA: - Es el tuyo.

DON JUAN: - ;Muerto yo!

ESTATUA: - El capitán te mató

A la puerta de tu casa.

José Zorrilla,

Don Juan Tenorio (1844)

(Cf. Borges, Bioy, 1955: 189)

\section{EL SOÑADO}

-Ahora está soñando. ¿Con quién sueña? ¿Lo sabes?

-Nadie lo sabe.

- Sueña contigo. Y si dejara de soñar, ¿qué sería de ti?

-No lo sé.

-Desaparecerías. Eres una figura de su sueño. Si ese rey despertara, te apagarías como una vela.

Lewis Carroll

(Cf. Valadés, 1970: 18)

\section{CONCLUSIÓN}

Partiendo de la tradición y evolución del teatro breve en España, nuestro estudio se ha centrado en la producción actual de piezas dramáticas breves, entre las cuales establecemos distinciones según parámetros de duración escenificable y extensión textual. Con tal propuesta distintiva, hemos destacado y analizado, por una parte, el denominado microteatro español, cuya representación de micropiezas parece haberse especializado en la mínima duración escenificable; y, por otra parte, lo hemos comparado y contrastado, atendiendo a su extensión y apariencia formal, con aquellos otros casos más próximos, colindantes o difíciles de distinguir dentro de la producción proteica del consolidado fenómeno genérico del microrrelato o microficción hispánica. Alrededor de tal producción microtextual, la cual puede resultar más problemática en su posible distinción genérica y/o formal, hay que tener en cuenta, no obstante, que la microficción se proyecta sobre intereses productivos más narrativos, prosísticos e (inter-)textuales, todo lo cual se aleja o distancia de la formulación de textos dramáticos elaborados o pensados realmente para su representación, tal y como así sucede con la producción de micropiezas analizadas dentro del panorama del microteatro español. 


\section{REFERENCIAS BIBLIOGRÁFICAS}

AA.VV. (2003). Teatro contra la guerra, Madrid, AAT.

AA.VV. (2006A). 60 obras de un minuto de 60 autores dramáticos andaluces, Sevilla, Consejería de Cultura. Consejería de Educación. Junta de Andalucía.

AA.VV. (2006B). Grita, tengo sida, Madrid, Publicaciones Universidad Complutense de Madrid.

AA.VV. (2013). «Teatro Breve: del entremés al happening», Anagnórisis. Revista de investigación teatral, 7.

Andres-Suńrez, Irene (200I). «Tendencias del microrrelato español», Romera Castillo, José, y Gutiérrez Carbajo, Francisco (eds.), El cuento en la década de los noventa, Madrid, Visor, pp. 659-673.

- (2010). El microrrelato español. Una estética de la elipsis, Palencia, Menoscuarto Ediciones.

- (20I4). «Transversalidad de las formas literarias breves», en http://www.mecd.gob.es/lectura/pdf/ v14_ire_andres_suarez.pdf (15-07-17).

Borges, Jorge Luis y Bioy Casares, Adolfo (eds.) (I955). Cuentos breves y extraordinarios, Buenos Aires, Editorial Raigal.

Díez Ménguez, Isabel Cristina (20I2). «Bibliografía del teatro breve español en los inicios del siglo XXI», Signa. Revista de la Asociación Española de Semiótica, n. ${ }^{\circ}$ 21, pp. 205-347.

Epple, Juan ARmando (20I0). «Teatro breve y minificción», Pollastri, Laura (ed.), La huella de la clepsidra. El microrrelato en el siglo xxi, Buenos Aires, Ediciones Katatay, pp. 133-143.

GoRdON, RAFAEL (2006). Teatro breve (1992-2004), Madrid, Fundamentos.

Gutiérrez Carbajo, Francisco (ed.) (2006). Cuadros de amor y humor, al fresco, de José Luis Alonso de Santos, Madrid, Cátedra.

- (2006). «Teatro breve en los inicios del siglo xxi: Los cuadros de Alonso de Santos», Romera Castillo, José (ed.), Tendencias escénicas al inicio del siglo xxi, Madrid, Visor, pp. 225-246.

- (ED.) (20I3). Teatro breve actual, Barcelona, Castalia.

Huerta Calvo, Javier (2008). Historia del teatro breve en España, Madrid, Iberoamericana, pp. 19-26.

Koch, M. Dolores (I98I). «El micro-relato en México: Torri, Arreola, Monterroso y Avilés Fabila», Hispamérica, X/30, pp. 123-130.

Lagamanovich, David (ed.) (2005). La otra mirada. Antología del microrrelato hispánico, Palencia, Menoscuarto Ediciones.

Méndez Moya, Adelardo (2003). «A propósito de pulgas dramáticas; Trece minipiezas y un happening de Javier García Teba», Trece mininipiezas y un happening, Javier García Teba, Cádiz, Fundación Vipren, pp. 15-21.

Moreno Arenas, José (2003). Teatro mínimo (pulgas dramáticas), Granada, Dauro.

Obligado, Clara (ed.) (200 I). Por favor, sea breve. Antología de relatos hiperbreves, Madrid, Páginas de Espuma.

- (ed.) (2009). Por favor, sea breve 2. Antología de microrrelatos, Madrid, Páginas de Espuma.

Orozco Vera, María Jesús (2006). «Teatro breve del nuevo milenio: claves temáticas y artísticas», Romera Castillo, José (ed.), Tendencias escénicas al inicio del siglo xxi, Madrid, Visor, pp. 721-734.

- (2007). «El teatro breve y la puesta en escena: "Los siete pecados capitales", espectáculo dirigido por Alfonso Zurro», Romera Castillo, José (ed.), Análisis de espectáculos teatrales (2000-2006), Madrid, Visor, pp. 431-443.

Quiles, Eduardo (200I). «Teatro corto. ¿Cuestión de folios o de síntesis?», Art Teatral, n. ${ }^{\circ}$ 15, en www.artteatral.com (15-07-17).

Ródenas DE Moya, Domingo (2009). «La microtextualidad en la vanguardia histórica», Montesa, Salvador (ed.), Narrativas de la posmodernidad. Del cuento al microrrelato, Málaga, AEDILE, pp. 67-90. 
Serrano, Virtudes (ed.) (2004). Teatro breve entre dos siglos: Antología, Madrid, Cátedra.

TARIO, Francisco (I952). Tapioca Inn: mansión para fantasmas, México, FCE.

TOMEO, JAVIER (1996). Historias mínimas, Barcelona, Anagrama (1. a ed., Barcelona, Mondadori, 1988).

VAladÉs, EdMundo (ed.) (1970). El libro de la imaginación. Antología de prodigios, fantasías, agudezas y ficciones breves, México D.F., Universidad de Guanajuato.

Zavala, Lauro (2004). Cartografías del cuento y la minificción, Sevilla, Editorial Renacimiento.

Zurro, Alfonso (1994). Bufonerías. Teatro para cómicos de la lengua, Sevilla, Galaor. 